\title{
PROSES NORMALIZING DAN TEMPERING PADA SCMnCr2 UNTUK MEMENUHI STANDAR JIS G 5111
}

\author{
Agung Setyo Darmawan, Masyrukan, Riski Ariyandi \\ Teknik Mesin Universitas Muhammadiyah Surakarta \\ Jl. A. Yani Tromol Pos I Pabelan Kartasura \\ E-mail:agungsetyod@yahoo.com
}

\begin{abstract}
ABSTRAK
Baja SCMnCr merupakan baja produk pengecoran produksi PT. Baja Kurnia Klaten. Untuk mengetahui apakah baja ini sudah memenuhi standar kekuatan JIS G 5111 dengan kekuatan tarik minimum $590 \mathrm{~N} / \mathrm{mm}^{2}$, maka dilakukan pengujian struktur mikro dan kekuatan pada raw material. Pengujian kekuatan pada raw material baja ini memperlihatkan hasil dibawah standar yaitu kekuatan tariknya $539.21 \mathrm{~N} / \mathrm{mm}^{2}$. Oleh karena itu dilakukan proses normalizing dan tempering pada baja SCMnCr2 untuk memenuhi standar tersebut. Sesudah dilakukan proses heat treatment Baja SCMnCr2 diuji strukturmikro dan kekuatan tariknya. Foto struktur mikro baja SCMnCr2 setelah dinormalizing dan kemudian ditempering memperlihatkan butir yang lebih kecil dibanding raw materialnya.. Setelah dilakukan normalizing dan tempering harga kekuatan naik menjadi $685.51 \mathrm{~N} / \mathrm{mm} 2$ dan akan menurun menjadi $664.21 \mathrm{~N} / \mathrm{mm}^{2}$ ketika waktu penahanan tempering diperlama menjadi 45 menit. Hal ini disebabkan karena meningkatnya ukuran butir ferit dan perlit.
\end{abstract}

Kata kunci: SCMnCr2, Normalizing, Tempering, JIS G 5111

\section{PENDAHULUAN}

Pemakaian baja dalam kehidupan masyarakat dan dunia industri mensyaratkan faktor sifat mekanik tertentu yang sesuai dengan standar. JIS (Japanese Industrial Standard) adalah salah satu dari beberapa macam standarisasi di dunia. JIS sendiri dikeluarkan oleh negara Jepang sebagai salah satu acuan dalam dunia teknik. Standarisasi ini digunakan agar produk baja dapat digunakan secara aman.

Sifat mekanik, sebagai contoh, kekuatan tarik dipengaruhi oleh ukuran butir. Perlakuan Panas (Heat treatment) dapat digunakan untuk mengatur ukuran butir dan meningkatkan sifat mekanik material [Anderson, 2003]. ). Definisi perlakuan panas adalah pengubahan struktur- mikro, dengan memberikan pemanasan dan mengatur laju pendinginan sehingga diperoleh strukturmikro yang diinginkan. Yang tidak berubah pada proses perlakuan panas ini adalah komposisi bahan. Sedang definisi strukturmikro sendiri adalah konfigurasi distribusi fasa untuk suatu komposisi tertentu.

Contoh proses perlakuan panas adalah full anealling, normalizing, dan tempering. Pada full anealling dan normalizing baja karbon, semakin cepat laju pendinginan, semakin kecil butir yang terjadi [Callister Jr., 2007].

Full anneal adalah pemanasan baja ke temperatur $30^{\circ} \mathrm{C}$ diatas garis $\mathrm{A}_{3}$ atau $\mathrm{A}_{1}$ (tergantung pada kandungan karbon), ditahan pada temperatur tersebut untuk mendapatkan fasa 
austenit yang homogen, kemudian didinginkan secara lambat pada tungku. Hasil unluk baja hypoeutectoid adalah perubahan fasa dari austenit ke perlit lamellar kasar (butir besar) vang lunak, bebas tegangan, dan ferit yang halus. Kata pelunakan (annealing) saja jika digunakan pada paduan besi $(\mathrm{Fe})$ menunjukkan proses full anneal. Jika digunakan pada paduan non besi kata pelunakan (annealing) menyatakan perlakuan panas yang dirancang untuk melunakkan struktur hasil pengerjaan dingin dengan rekristalisasi dan atau kemudian pertumbuhan butir.

Karena memerlukan waktu yang lama dan mahal, dalam beberapa kasus full anneal diganti dengan normalizing. Pada normalizing, pendinginan dilakukan di udara (laju pendinginan lebib cepat dibandingkan ditungku) dan menghasilkan struktur perlit yang halus. Baja di normalizing untuk mendapatkan kekerasan dan kekuatan yang lebih besar dibanding jika dengan full anneal.

Tempering pada baja dilakukan dengan memanaskannya pada temperatur sedikit $723^{\circ} \mathrm{C}$. Perlakuan panas ini umumnya dilakukan setelah proses celup cepat (quenching). Tujuan dari tempering adalah untuk mendapatkan baja yang lebih tangguh (tough) dan juga liat (ductile) tanpa banyak mengurangi kekuatan (strength).

\section{TINJAUAN PUSTAKA}

Menurut Widyatmadji (2001), perlakuan panas normalizing memberikan perubahan terhadap struktur mikro dan kekuatan baja. Makin tinggi temperatur austenisasi dan makin lama waktu tahan, kekuatan baja makin menurun, namun ketangguhannya akan meningkat.

Mulyanti (1996) meneliti pengaruh perlakuan panas pada paduan baja mangan austenit dimana kekerasan akan turun dan harga impak akan naik jika dilakukan proses temper, disebutkan juga bahwa dengan naiknya temperatur austenitisasi, maka kekerasan akan turun dan harga impak akan naik.

\section{METODOLOGI PENELITIAN Diagram Alir Penelitian}

Penelitian dilakukan sesuai diagram alir penelitian seperti terlihat pada gambar 1 .
Material yang akan diuji adalah Low Alloy Steel Casting, SCMnCr2 produksi PT. BAJA KURNIA Ceper Klaten. Pembuatan specimen uji tarik mengikuti standar JIS Z 2201.

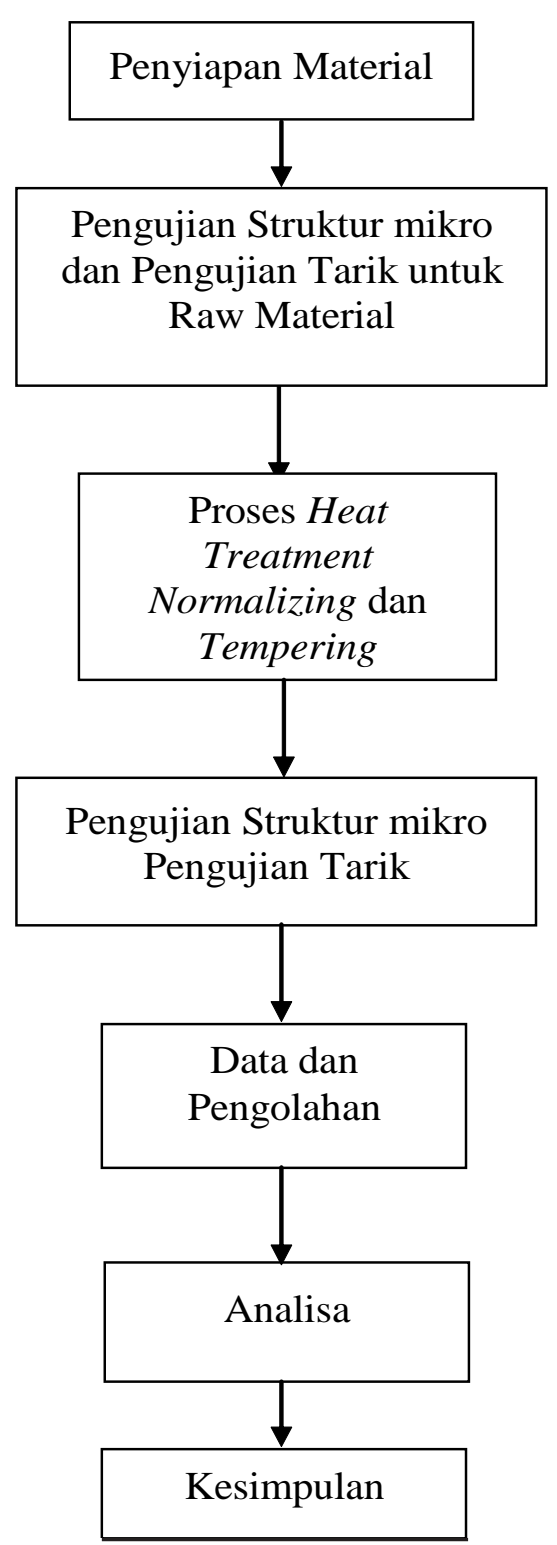

\section{Gambar 1. Diagram Alir Penelitian}

\section{Pelaksanaan Heat Treatment}

Heat Treatment yang terdiri dari dua proses yaitu normalizing dan tempering dilaksanakan sesuai gambar 2, dengan temperatur pemanasan $850^{\circ} \mathrm{C}$ untuk temperatur Austenitisasi dan $600^{\circ} \mathrm{C}$ untuk temperatur tempering. Adapun proses heat treatment yang dilakukan pada 
potongan material sebelum dibentuk benda uji (specimen) adalah sebagai berikut :

1. Spesimen dimasukkan ke dalam tungku pemanas (furnace), kemudian tungku pemanas di set pada temperatur $850^{\circ} \mathrm{C}$, setelah temperatur tungku pemanas mencapai $850^{\circ} \mathrm{C}$, spesimen ditahan selama 40 menit dalam suhu tersebut.

2. Setelah tertahan selama 40 menit dalam temperatur $850^{\circ} \mathrm{C}$, specimen dikeluarkan dari tungku pemanas dan didinginkan diudara luar hingga mencapai suhu kamar (proses normalizing).

3. Kemudian dilanjutkan dengan proses tempering yakni dengan langkah awal mengeset tungku pemanas pada temperatur 600Ú C lalu ditahan dengan variasi waktu 20 menit (specimen A), 30 menit (specimen B), dan 45 menit (specimen C).
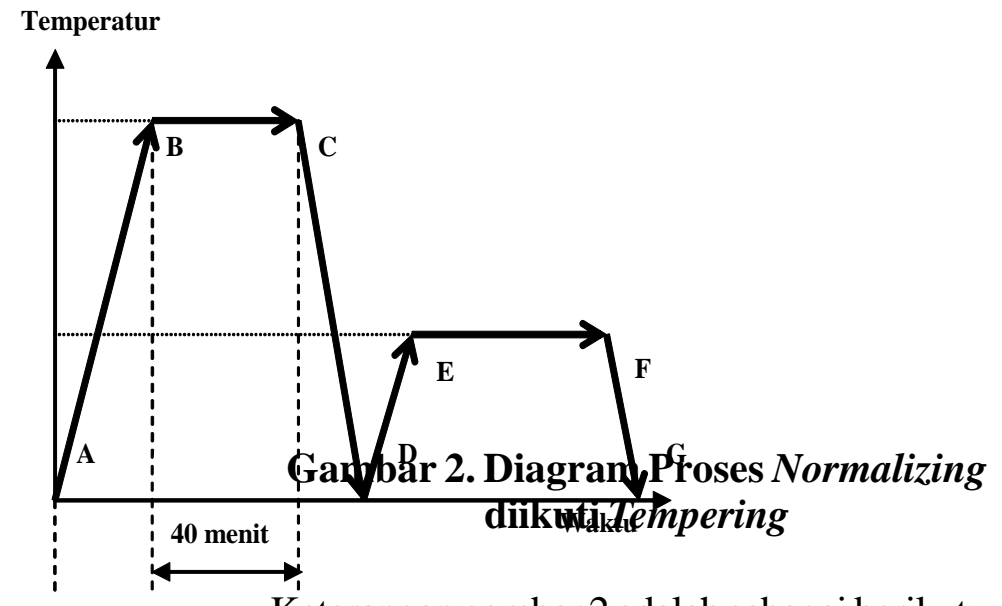

Keterangan gambar 2 adalah sebagai berikut:

Garis $\mathrm{AB}=$ Proses pemanasan hingga mencapai temperatur $850^{\circ} \mathrm{C}$.

Garis $\mathrm{BC}=$ Proses penahanan pada temperatur $850^{\circ} \mathrm{C}$ selama 40 menit.

Garis CD $=$ Proses normalizing (pendinginan dengan udara sampai temperatur kamar, 26 ${ }^{\circ} \mathrm{C}$ ).

Garis DE $=$ Proses pemanasan hingga temperatur $600^{\circ} \mathrm{C}$.
Garis EF = Proses penahanan pada temperatur (a) selama 20 menit untuk specimen $\mathrm{A}$ (b) selama 30 menit untuk specimen B (c) selama 45 menit untuk specimen $\mathrm{C}$.

Garis FG $=$ Proses pendinginan dengan udara sampai temperatur kamar di udara terbuka.

\section{HASIL DAN PEMBAHASAN}

\section{Hasil dan Analisa Data Hasil Pengujian Struktur Mikro.}

Struktur mikro ini dilihat dengan Olympus Metallurgical Microscopes dengan pembesaran 200 kali, dari pemotretan dengan kamera didapatkan gambar 3, 4,5 dan 6 .

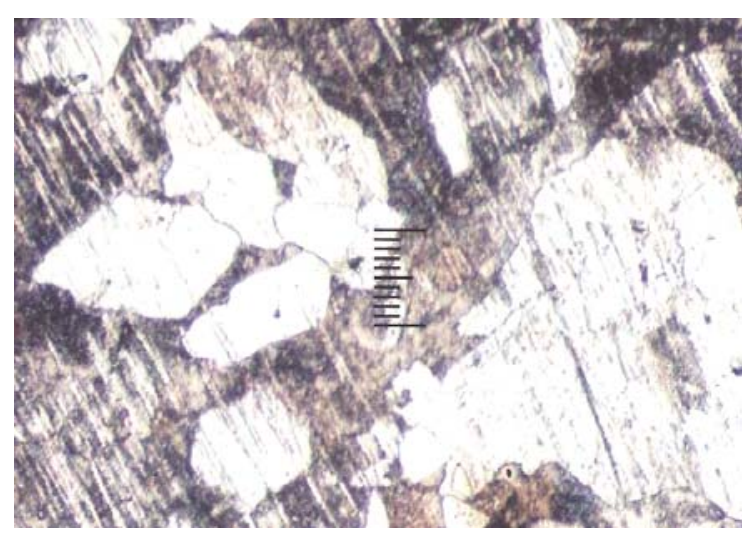

\section{Gambar 3. Struktur Mikro dari Raw Material}

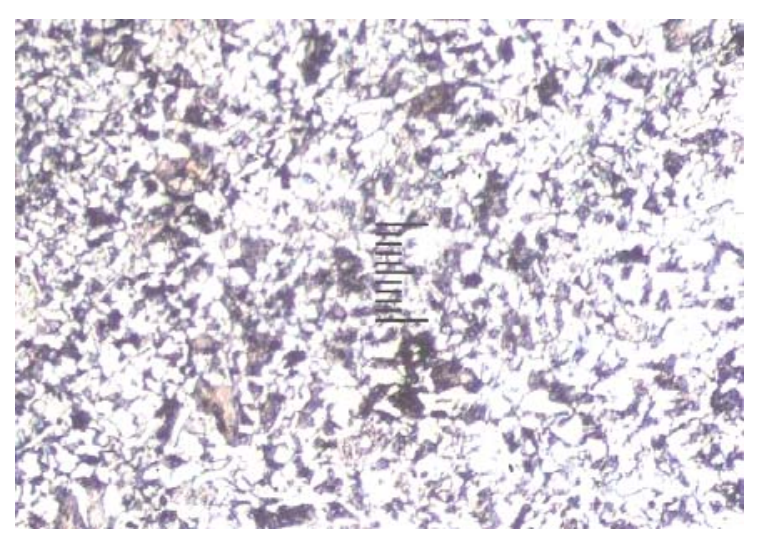

Gambar 4. Struktur Mikro dari Specimen A 


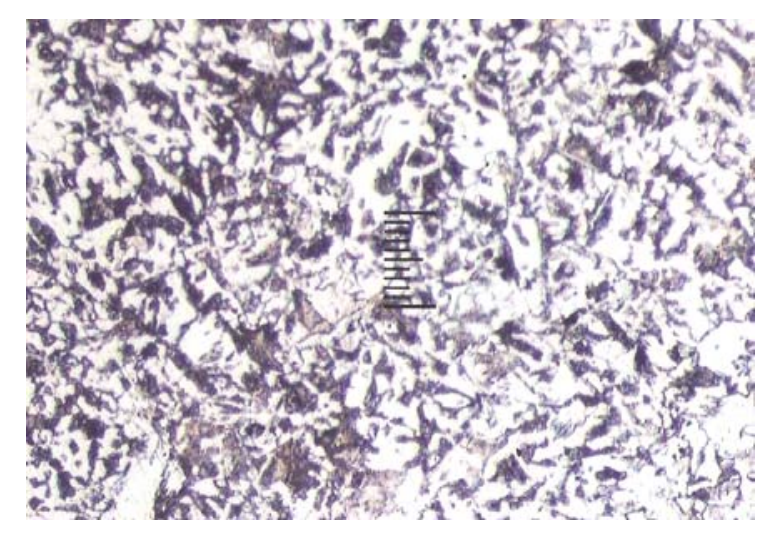

Gambar 5. Struktur Mikro dari Specimen B

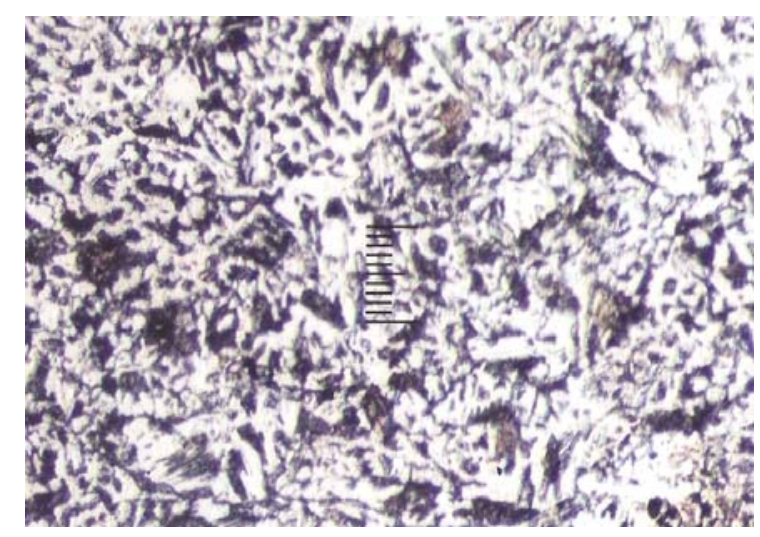

\section{Gambar 6. Struktur Mikro dari Specimen $\mathrm{C}$}

Dari gambar 3, 4, 5, dan 6 dapat diketahui bahwa fasa yang terjadi pada material ini adalah fasa ferit (bagian yang terang) dan pearlit (bagian yang gelap) dan setelah diproses heat treatment (tempering after normalizing) ukuran butir berubah lebih kecil. Hal ini disebabkan karena laju pendinginan proses normalizing lebih cepat dari pada laju pendinginan pada proses pengecoran raw material.

\section{Hasil dan Analisa Data Hasil Pengujian Kekuatan Tarik}

Kekuatan tarik untuk baja SCMnCr2 berdasarkan standar JIS G 5111 adalah minimum $590 \mathrm{kgf} / \mathrm{mm}^{2}$. Data hasil pengujian tarik dapat dilihat pada tabel 1. Diagram alir tegangan- regangan teknik hasil pengujian tarik di perlihatkan pada gambar 7. Gambar 8 memperlihatkan perbandingan kekuatan tarik maksimum dari ScMnCr2 sebelum dan sesudah proses treatment.

\section{Tabel 1. Data Hasil Uji Tarik Bahan ScMnCr2 Sebelum dan Sesudah Proses Treatmen.}

\begin{tabular}{|c|c|c|}
\hline Spesimen & $\begin{array}{c}\text { Kekuatan } \\
\text { Luluh } \\
\left(\mathrm{N} / \mathbf{m m}^{2}\right) \\
\end{array}$ & $\begin{array}{c}\text { Kekuatan } \\
\text { Tarik } \\
\left(\mathrm{N} / \mathbf{m m}^{2}\right) \\
\end{array}$ \\
\hline $\mathrm{RM}$ & 434.44 & 539.21 \\
\hline A & 387.35 & 685.51 \\
\hline B & 388.16 & 674.16 \\
\hline $\mathrm{C}$ & 383.20 & 664.21 \\
\hline
\end{tabular}

Keterangan:

RM : Raw Material

A : Spesimen Treatment Temperatur Austenitisasi $850^{\circ} \mathrm{C}$ Normalizing + Temper $600^{\circ} \mathrm{C} 20$ menit

B : Spesimen Treatment Temperatur Austenitisasi $850^{\circ} \mathrm{C}$ Normalizing + Temper $600^{\circ} \mathrm{C} 30$ menit

$\mathrm{C}$ : Spesimen Treatment Temperatur Austenitisasi $850^{\circ} \mathrm{C}$ Normalizing + Temper $600^{\circ} \mathrm{C} 45$ menit

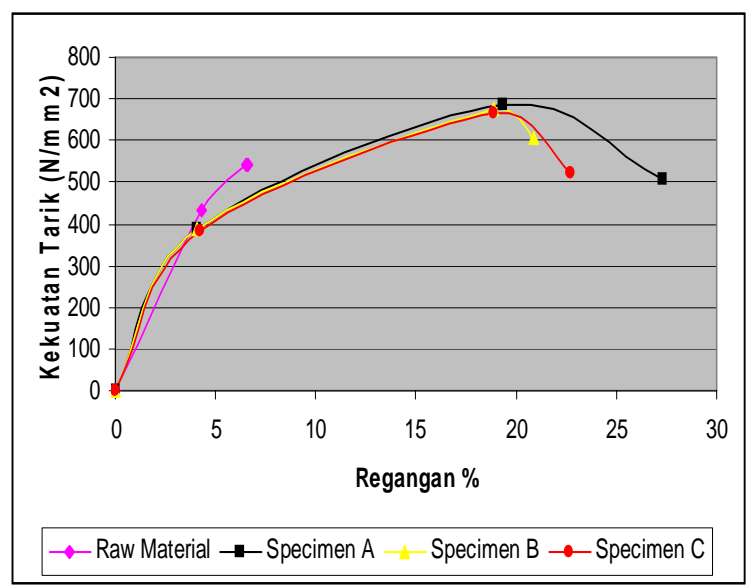

Gambar 7. Diagram Alir TeganganRegangan Teknik Hasil Pengujian Tarik 


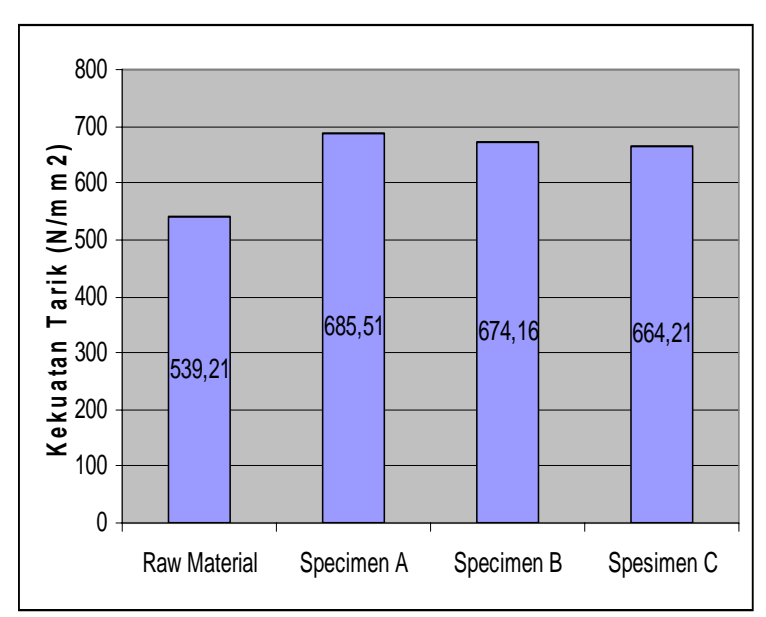

\section{Gambar 8. Perbandingan Kekuatan Tarik Sebelum dan Sesudah Proses Heat Treatment}

Dari data-data hasil pengujian kekuatan tarik dapat diketahui bahwa harga kekuatan tarik specimen ScMnCr2 produk PT. Baja Kurnia sebelum di treatment belum memenuhi standar JIS G 5111 (590 N/mm²). Dan proses heat treatment (normalizing dilanjutkan proses tempering dengan tiga variasi waktu) mengakibatkan kenaikan kekuatan tarik specimen sehingga standar JIS G 5111 terpenuhi. Kenaikan kekuatan tarik ini disebabkan oleh terbentuknya butir-butir yang lebih halus (gambar 2, 3, dan 4). Semakin lama waktu tempering maka kekuatan tarik specimen akan menurun karena butir-butirnya membesar.

\section{SIMPULAN}

Dari hasil pengujian kekuatan tarik dapat diketahui bahwa harga kekuatan tarik specimen ScMnCr2 produk PT. Baja Kurnia belum memenuhi standar JIS G 5111, yang mempunyai harga kekuatan tarik minimum yakni $590 \mathrm{~N} / \mathrm{mm}^{2}$. Dan proses heat treatment (tempering after normalizing) mengakibatkan kekuatan tarik specimen naik memenuhi standar JIS G 5111, akan tetapi lama waktu tempering juga berpengaruh menurunkan harga kekuatan tarik.

\section{DAFTAR PUSTAKA}

Anderson, J.C., 2003, Material Science for Engineers, Nelson Thornes, Cheltenham

Widyatmadji, 2001, Pengaruh Perlakuan Panas Normalisasi Terhadap Sifat Mekanik Dan Struktur Mikro Baja 1K3816AT Untuk Aplikasi Casing \& Tubing Spesifikasi API 5CT K55, UI, Jakarta

Callister, Jr., William D., 2007, Materials Science and Enginering; An Introduction, John Wiley \& Sons, New York

Mulyanti, 1996, Pengaruh Kadar Mangan (Mn) Dan Perlakuan Panas Terhadap Sifat Mekanis Dan Struktur Mikro Paduan Baja Mangan Austenit, UI Jakarta 